\title{
Identification and Characterization of Rice OsHKT1;3 Variants
}

\author{
Shahin Imran ${ }^{1,2} \mathbb{D}$, Yoshiyuki Tsuchiya ${ }^{1} \mathbb{D}$, Sen Thi Huong Tran 1,3 (D) and Maki Katsuhara ${ }^{1, *(\mathbb{D})}$ \\ 1 Institute of Plant Science and Resources, Okayama University, 2-20-1 Chuo, Kurashiki 710-0046, Japan; \\ ptj87a5q@s.okayama-u.ac.jp or shahin.imran@kau.edu.bd (S.I.); y-tsuchi@okayama-u.ac.jp (Y.T.); \\ pota42or@s.okayama-u.ac.jp (S.T.H.T.) \\ 2 Department of Agronomy, Khulna Agricultural University, Khulna 9100, Bangladesh \\ 3 Faculty of Agronomy, University of Agriculture and Forestry, Hue University, Hue 530000, Vietnam \\ * Correspondence: kmaki@okayama-u.ac.jp; Tel.: +81-086-434-1221; Fax: +81-086-434-1249
}

\section{check for} updates

Citation: Imran, S.; Tsuchiya, Y.; Tran, S.T.H.; Katsuhara, M. Identification and Characterization of Rice OsHKT1;3 Variants. Plants 2021, 10, 2006. https://doi.org/10.3390/ plants10102006

Received: 1 September 2021

Accepted: 21 September 2021

Published: 24 September 2021

Publisher's Note: MDPI stays neutral with regard to jurisdictional claims in published maps and institutional affiliations.

Copyright: (c) 2021 by the authors. Licensee MDPI, Basel, Switzerland. This article is an open access article distributed under the terms and conditions of the Creative Commons Attribution (CC BY) license (https:// creativecommons.org/licenses/by/ $4.0 /)$.

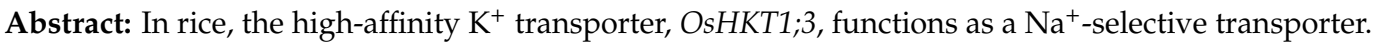
mRNA variants of OsHKT1;3 have been reported previously, but their functions remain unknown. In this study, five OsHKT1;3 variants (V1-V5) were identified from japonica rice (Nipponbare) in addition to OsHKT1;3_FL. Absolute quantification qPCR analyses revealed that the transcript level of OsHKT1;3_FL was significantly higher than other variants in both the roots and shoots. Expression levels of OsHKT1;3_FL, and some variants, increased after $24 \mathrm{~h}$ of salt stress. Two electrode voltage clamp experiments in a heterologous expression system using Xenopus laevis oocytes revealed that oocytes expressing OsHKT1;3_FL and all of its variants exhibited smaller $\mathrm{Na}^{+}$currents. The presented data, together with previous data, provide insights to understanding how OsHKT family members are involved in the mechanisms of ion homeostasis and salt tolerance in rice.
\end{abstract}

Keywords: $\mathrm{Na}^{+}$transport; rice; OsHKT1;3; mRNA variants; TEVC

\section{Introduction}

Salinity is a dominant abiotic stress that decreases crop growth and productivity to a great extent [1-4]. Salt stress imposes ion toxicity, osmotic stress, metabolic disturbance imbalance, and a significant decrease in plant yield [5-8]. Among cereals, rice (Oryza sativa L.) is one of the most consumed staple crops around the world, and it is sensitive to salinity stress at different growth stages $[9,10]$.

High-affinity potassium transporters (HKTs) are responsible for ion homeostasis and salt tolerance in plants [11-13]. Plant HKTs are divided into three classes: class 1 HKT proteins (HKT1s) function mainly as $\mathrm{Na}^{+}$-selective transporters, and they are present in both monocotyledonous and dicotyledonous plants; class 2 HKT proteins (HKT2s) function mainly as $\mathrm{Na}^{+}-\mathrm{K}^{+}$symporters, and are present only in monocotyledonous plants; class 3 HKT proteins (HKT3s) are present in mosses and clubmosses, and their selectivity for $\mathrm{Na}^{+}$ and /or $\mathrm{K}^{+}$is not yet clearly understood [14-18]. TaHKT2;1 was the first HKT characterized, and it has dual functions as a high-affinity $\mathrm{Na}^{+}-\mathrm{K}^{+}$symporter or a low-affinity $\mathrm{Na}+$ transporter according to the external $\mathrm{Na}+$ concentration $[19,20]$. There is extensive evidence indicating the central role of $H K T$ genes as $\mathrm{Na}^{+}$and $\mathrm{Na}^{+} / \mathrm{K}^{+}$transporters in controlling $\mathrm{Na}^{+}$accumulation and salt tolerance in the halophytic turf grass, Sporobolus virginicus, as well as Arabidopsis thaliana, barley, soybeans, and rice [21-27]. Seven functional HKT genes from rice have been identified. Among them, OsHKT1;1, OsHKT1;3, OsHKT1;4, and OsHKT1;5 were shown to be $\mathrm{Na}^{+}$-selective [22,28-32]. In addition, the OsHKT1;1 gene was identified as a determinant of salt tolerance in rice [33]. An OsHKT1;1 isoform from indica induced higher inward $\mathrm{Na}^{+}$currents than the japonica-predominant isoform in a heterologous Xenopus laevis oocyte expression system [34]. OsHKT1;4 mediated robust $\mathrm{Na}^{+}$ transport in yeast cells and X. laevis oocytes [35]. Moreover, OsHKT1;4 was involved in $\mathrm{Na}^{+}$ accumulation in the rice shoots, especially in reproductive tissues, upon salt stress [35,36]. 
OsHKT1;3 was identified as a $\mathrm{Na}^{+}$-selective transporter [29], and its expression was detected in the cortex and vascular tissue of the roots and leaves. Transcripts of OsHKT1;3 were also detected in both salt-tolerant Pokkali and salt-sensitive Nipponbare cultivars [37]. In addition, a high expression of OsHKT1;3 was detected in a Cheongcheong rice cultivar [38]. Abdulhussein et al. [39] reported that the OsHKT1;3 gene played a role in the accumulation of $\mathrm{Na}^{+}$in old leaves. OsHKT1;3 did not show any type of transport activity in yeast cells but mediated both inward and outward $\mathrm{Na}^{+}$currents in X. laevis oocytes [28-30]. According to Sundstrom [40], the OsHKT1;3 produced a splice variant in addition to the full-length OsHKT1;3. However, the function of the variant is not yet known.

In the present study, we confirmed OsHKT1;3 variants in a salt-sensitive japonica rice, Nipponbare, analyzed their expression patterns, and characterized transport properties using two electrode voltage clamp (TEVC) experiments using X. laevis oocytes, to discuss new aspects of OsHKT1;3 variants.

\section{Results}

\subsection{OsHKT1;3 cDNAs Isolation and Characterization}

Using primers for the full-length clone of OsHKT1;3, several fragments were amplified from cDNAs prepared from the whole seedling of the japonica rice variety, Nipponbare (Figure 1A). The full-length OsHKT1;3 clone (OsHKT1;3_FL) comprised 1768 nucleotides, encoding a $59.2 \mathrm{kDa}$ polypeptide of 531 putative amino acid residues. The exon-intron structure of OsHKT1;3 was determined by aligning cDNA and genomic sequences, which contained two introns and three exons (Figure 1B, Supplementary Figure S2). In addition to the full-length sequence, five splicing variants were confirmed after sequencing. Five OsHKT1;3 variants (OsHKT1;3_V1, _V2,_V3, _V4, and _V5) comprised 1312, 1206, 958, 899, and 1010 nucleotides, encoding 42.6, 38.3, 15.8, 14.9, and $14.9 \mathrm{kDa}$ polypeptides, and containing 379, 342, 140, 132, and 132 putative amino acid residues, respectively (Figure 1B, Supplement Figures S3 and S4). Transmembrane domains (M1-M8), as indicated in Figure 1B, were predicted using previously registered data from the UniPort database (https:/ / www.uniprot.org/uniprot/Q6H501, accessed on 30 July 2021).

A

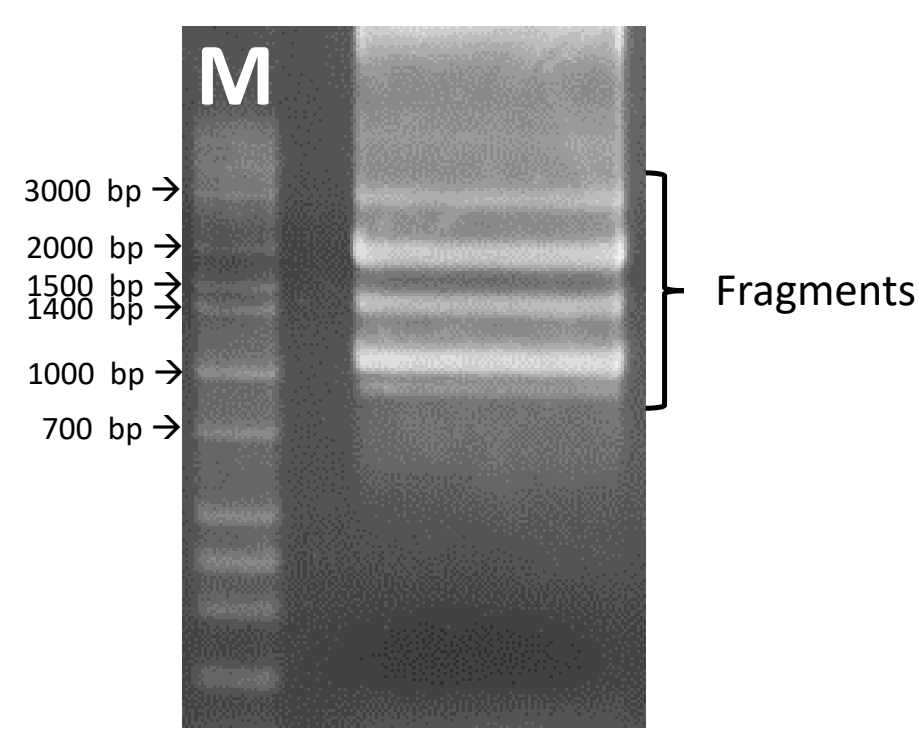

Figure 1. Cont. 
B

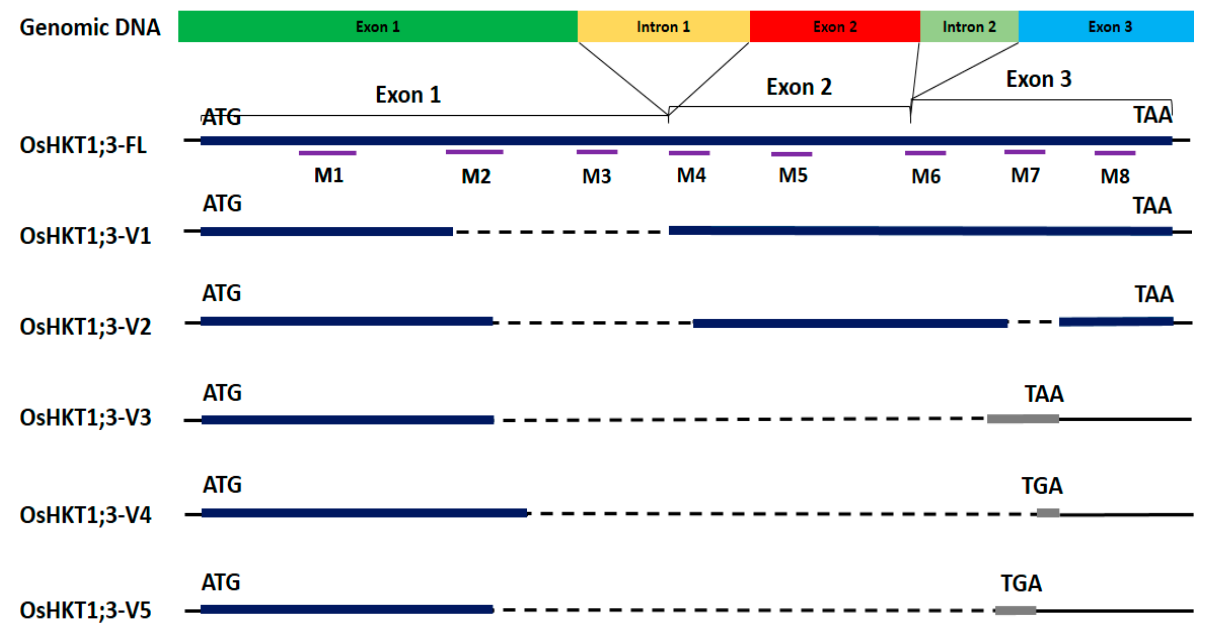

Figure 1. OsHKT1;3 transcripts identified in Nipponbare rice. (A) A gel image of RT-PCR products amplified with primers for OsHKT1;3. (B) Schematic diagrams of OsHKT1;3_FL and its variants. Bold lines indicate amino acid regions that were the same as FL (blue) or different from FL because of the frame shift (grey). The thin lines indicate non-translated regions, and dotted lines indicate missing nucleotide regions (gap) compared to the FL sequence. M1-M8 indicate transmembrane domains predicted using previously registered data from the UniPort database.

\subsection{Expression Profile of OsHKT1;3}

Fourteen-day-old Nipponbare rice plants were examined for the tissue-specific expression profiles of OsHKT1;3 in normal growth conditions. The mRNA amounts in the roots and shoots were determined using the absolute quantification method. As a result, the transcript level of OsHKT1;3_FL was significantly higher than other variants, and OsHKT1;3_V1 was lower in both the roots and shoots (Figure 2). No differences in the levels of transcripts were detected between the shoots and roots in the $\mathrm{FL}$, or in any variants at $p<0.05$ (data not shown).

A

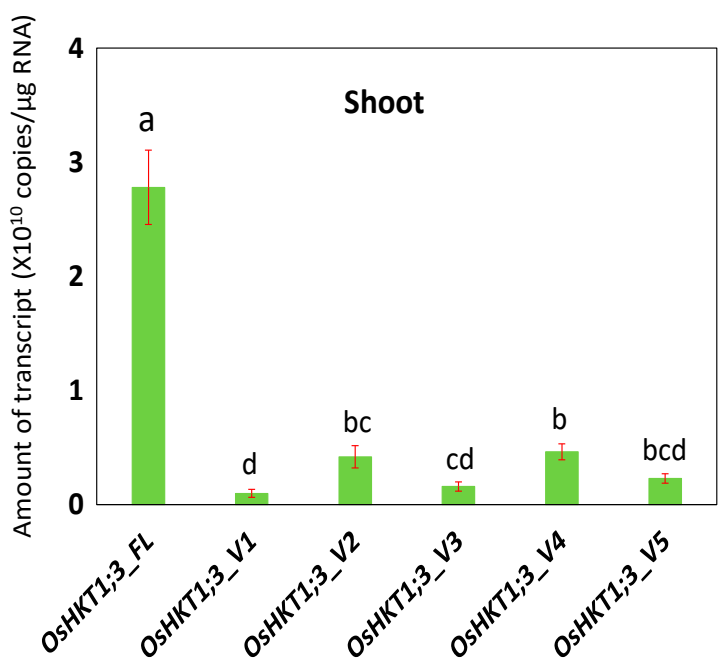

B

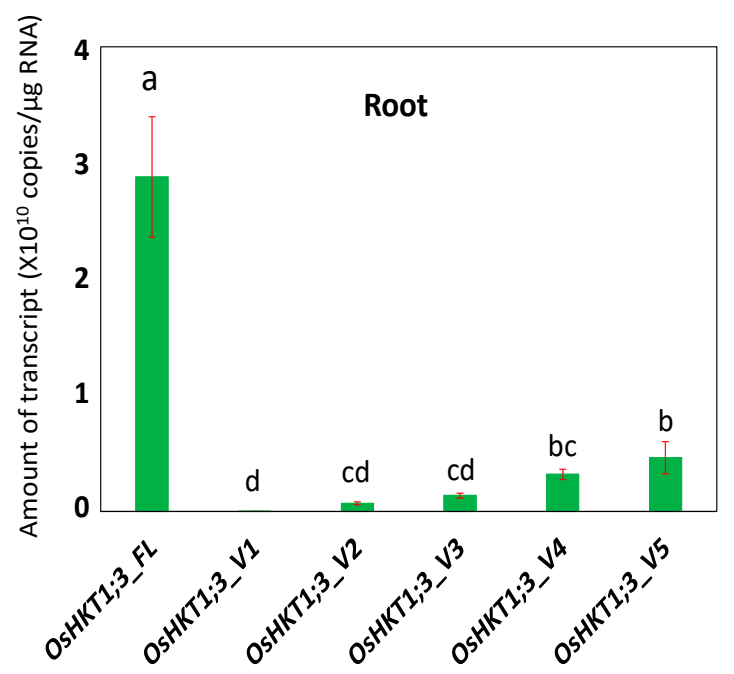

Figure 2. qPCR analyses on OsHKT1;3 transcripts in Nipponbare plants grown in normal growth conditions. Expression levels of OsHKT1;3_FL and its variants in the shoots (A) and roots (B) of 14-day-old plants were investigated by absolute quantification. Data are means $\pm \mathrm{SE}, n=3$. Two independent experiments were performed, and similar results were obtained. Significant differences were identified by one-way ANOVA, and different letters indicate significant differences $(p<0.05)$. 
All salt stress treatments induced a significantly higher expression of OsHKT1;3_FL in the shoots at $24 \mathrm{~h}$, but not at $48 \mathrm{~h}$ (Figure 3A). OsHKT1;3_FL transcript levels were significantly higher in the roots treated with $50 \mathrm{mM}$ and $100 \mathrm{mM} \mathrm{NaCl}$ at $24 \mathrm{~h}$, but not at $48 \mathrm{~h}$ (Figure 3B). OsHKT1;3_V1 and _V2 transcripts decreased in the shoots after salt stress treatment (Figure 3C,E). OsHKT1;3_V2 transcripts in the roots were significantly higher at $24 \mathrm{~h}$ with $50 \mathrm{mM}$ and $100 \mathrm{mM} \mathrm{NaCl}$, then decreased at $48 \mathrm{~h}$ (Figure 3F). No significant differences in OsHKT1;3_V3 transcripts were detected (Figure 3G,H). A significantly higher expression of OsHKT1;3_V4 was observed only in the shoots with salt stress treatment at $24 \mathrm{~h}$ (Figure 3I,J). OsHKT1;3_V5 transcript levels in the shoots at $24 \mathrm{~h}$ were significantly higher with salt stress treatment, but not at $48 \mathrm{~h}$ (Figure 3K). In the roots, OsHKT1;3_V5 showed significantly higher transcript levels only with $100 \mathrm{mM} \mathrm{NaCl}$ at $24 \mathrm{~h}$ (Figure 3L).

A

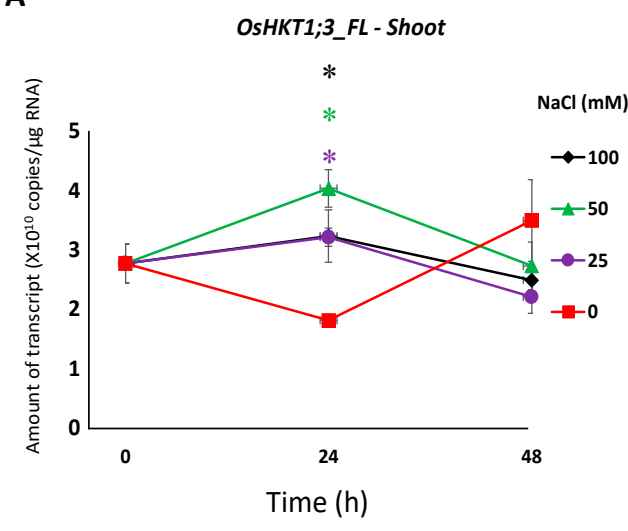

C

OsHKT1;3_V1 - Shoot

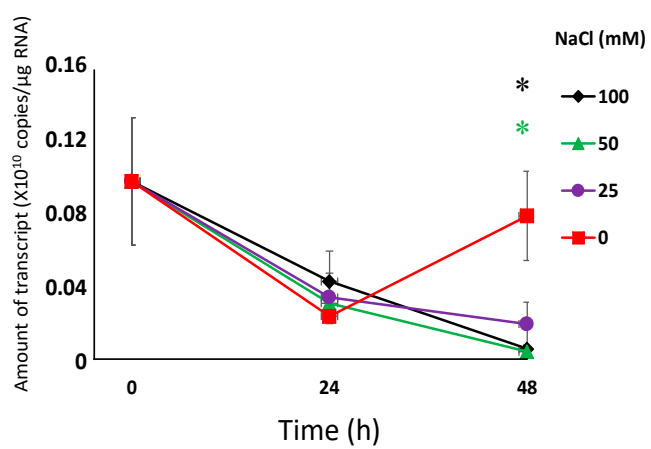

E

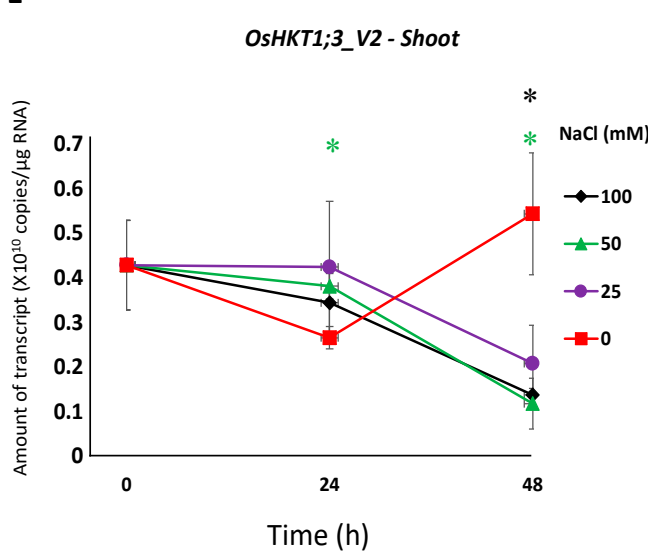

B

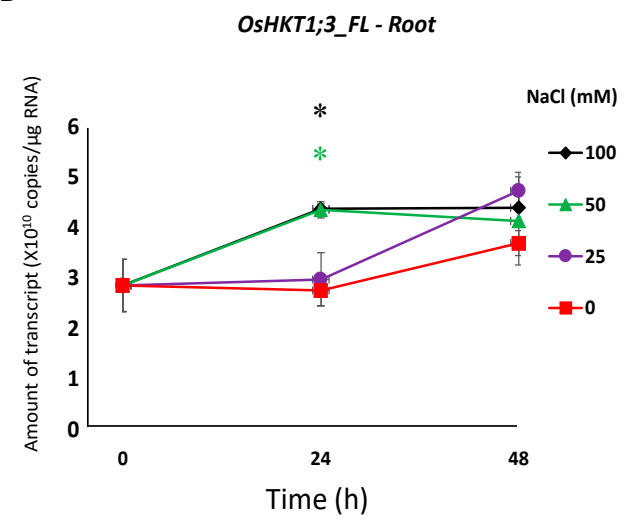

D

OsHKT1;3_V1 - Root

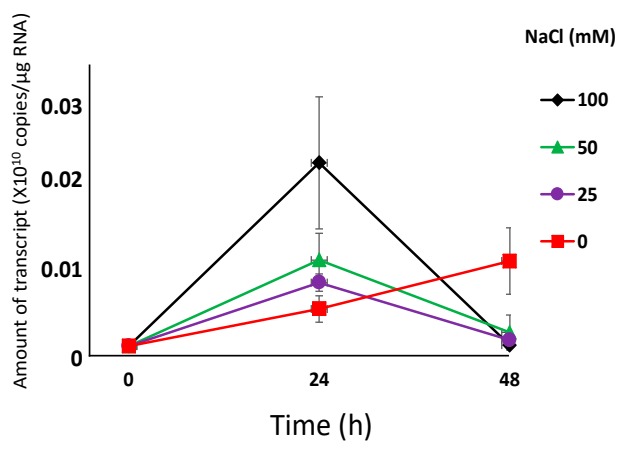

F

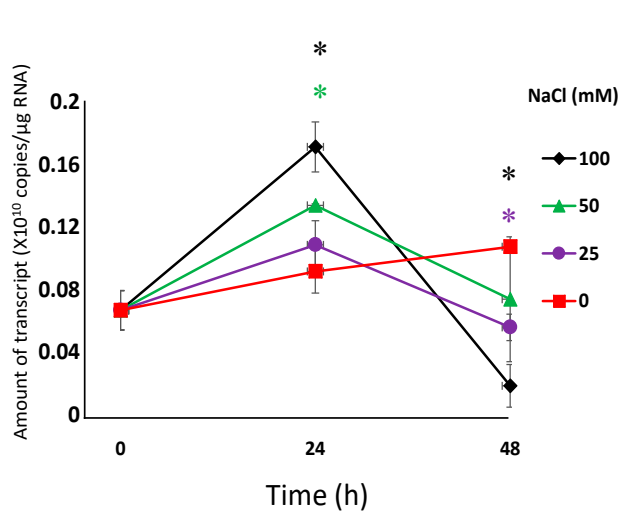

Figure 3. Cont. 
G

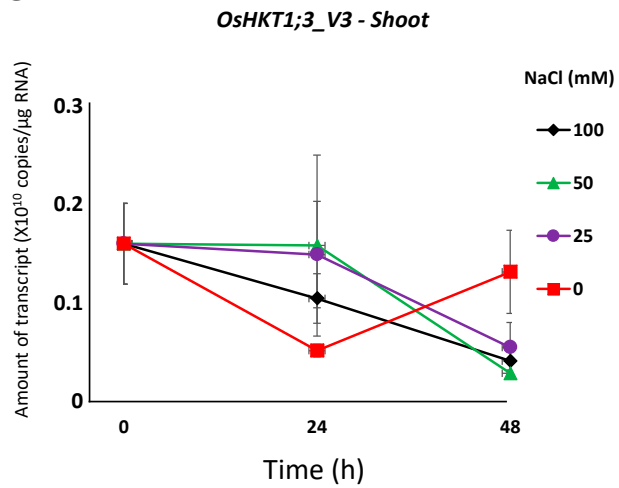

I

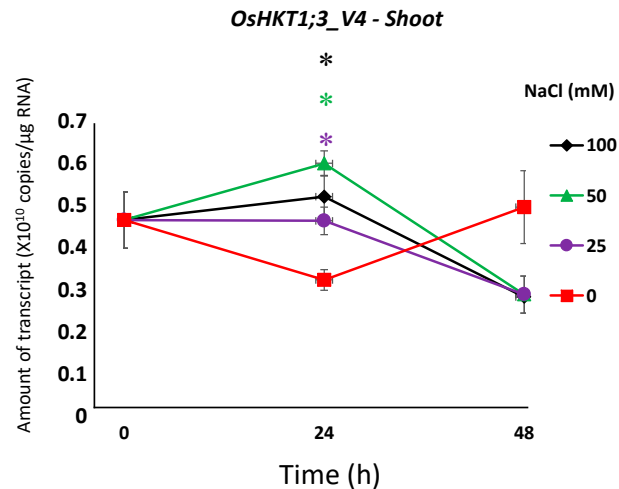

K

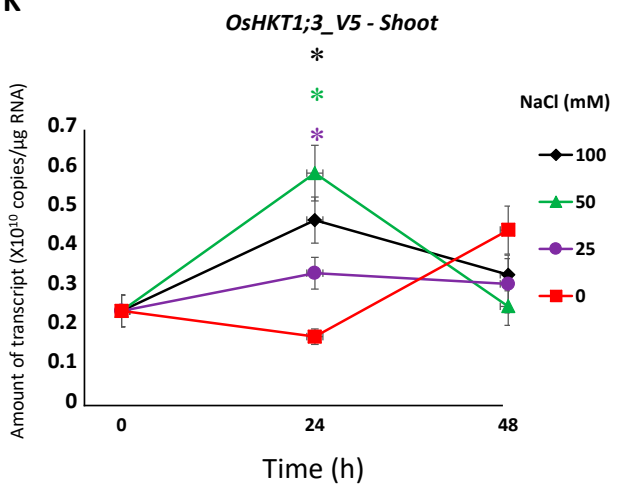

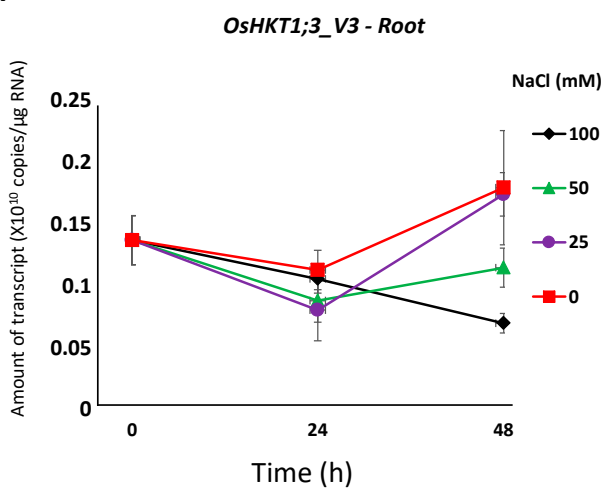

J

OsHKT1;3_V4 - Root

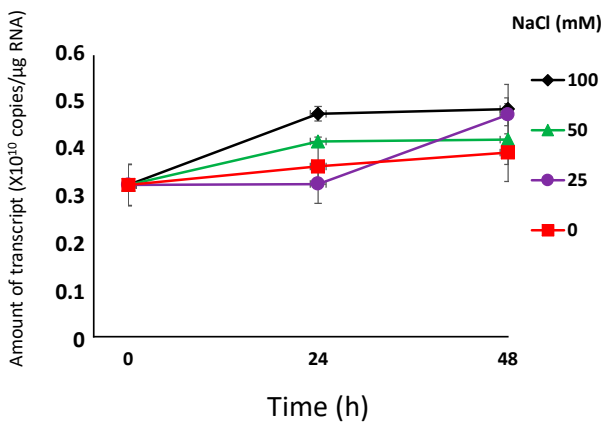

L

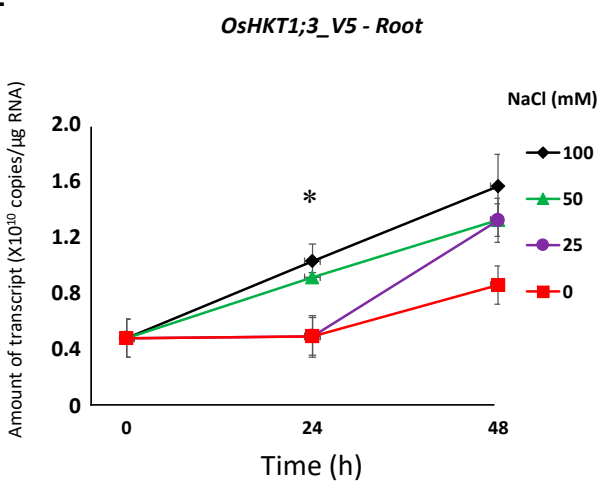

Figure 3. qPCR analyses of OsHKT1;3 transcripts in Nipponbare seedlings grown in salt-stressed conditions. Expression levels of OsHKT1;3_FL and each variant of the shoots and roots were investigated by absolute quantification. Fourteen-day-old Nipponbare plants were treated with (control) 0, 25, 50, and $100 \mathrm{mM} \mathrm{NaCl}$ solutions for 0,24 , and $48 \mathrm{~h}$ prior to total RNA extraction. (A) OsHKT1;3_FL-Shoot. (B) OsHKT1;3_FL-Root. (C) OsHKT1;3_V1-Shoot. (D) OsHKT1;3_V1-Root. (E) OsHKT1;3_V2-Shoot. (F) OsHKT1;3_V2-Root. (G) OsHKT1;3_V3-Shoot. (H) OsHKT1;3_V3-Root. (I) OsHKT1;3_V4-Shoot. (J) OsHKT1;3_V4-Root. (K) OsHKT1;3_V5-Shoot. (L) OsHKT1;3_V5-Root. Absolute amounts of transcripts (copies/ $\mu \mathrm{g}$ RNA) are shown. Data are means $\pm \mathrm{SE}, n=3$. Two independent experiments were performed, and similar results were obtained. An independent $t$-test was used to compare the expression. In each variant, data at $24 \mathrm{~h}$ from 3 stress conditions $(25,50$, and $100 \mathrm{mM} \mathrm{NaCl})$ were subjected to a $t$-test vs. control. If a significant difference $(p<0.05)$ was detected, such data were marked with an asterisk $\left(^{*}\right.$ ) and colored (purple for $25 \mathrm{mM} \mathrm{NaCl}$, green for $50 \mathrm{mM} \mathrm{NaCl}$, or black for $100 \mathrm{mM} \mathrm{NaCl})$. The same analyses were performed on data at $48 \mathrm{~h}$. 


\subsection{Ion Transport of OsHKT1;3_FL and Its Variant}

The ion-transporting activities of OsHKT1;3_FL and its variants were characterized using the TEVC method with X. laevis oocytes. As a result, OsHKT1;3_FL and its variants showed small inward $\mathrm{Na}^{+}$currents, indicating weak $\mathrm{Na}^{+}$-transporting activities (Figure 4A,B). Oocytes expressing OsHKT1;3_FL and all of its variants showed similar I-V curves and reversal potential. We performed TEVC measurements on OsHKT1;3_FL and all of its variants in a $\mathrm{K}^{+}$solution (Supplementary Figure S5), but no large $\mathrm{K}^{+}$-dependent currents were detected.
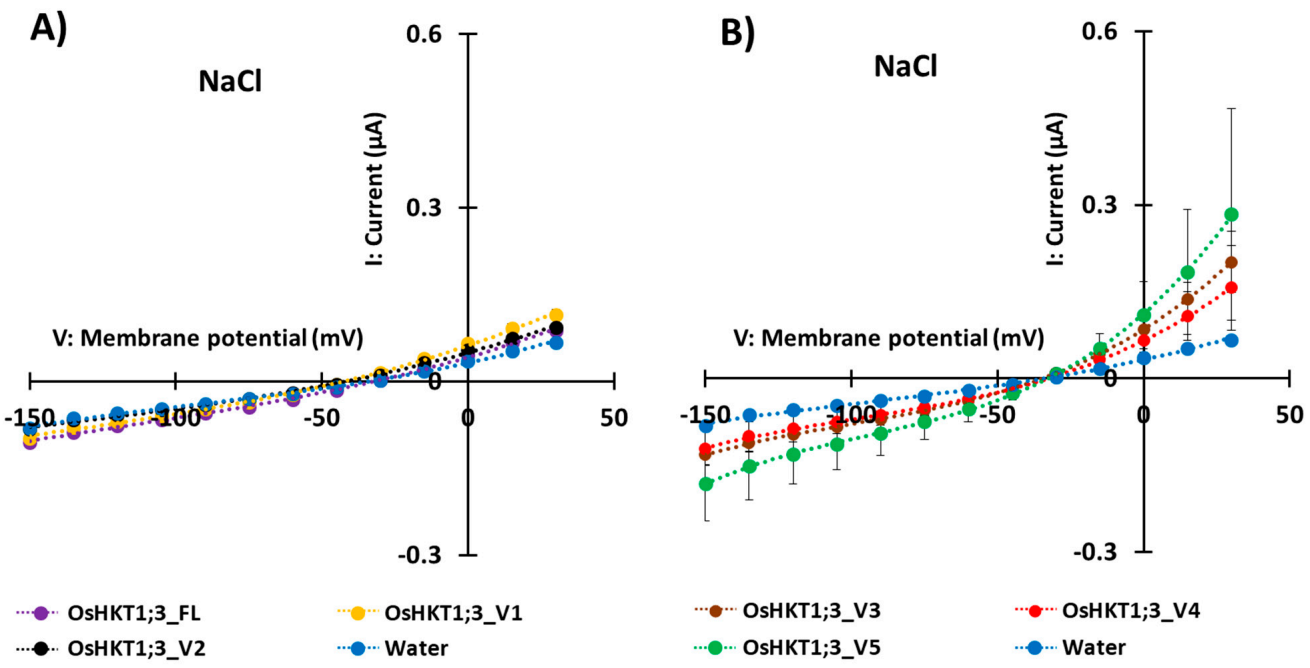

C)

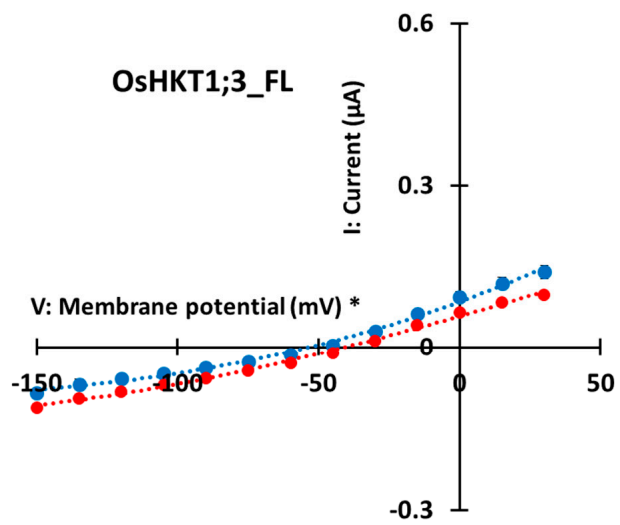

- $86.4 \mathrm{mM}$ choline- $\mathrm{Cl}+9.6 \mathrm{mM} \mathrm{NaCl}$

-...86.4 mM Na-Glu +9.6 mM NaCl

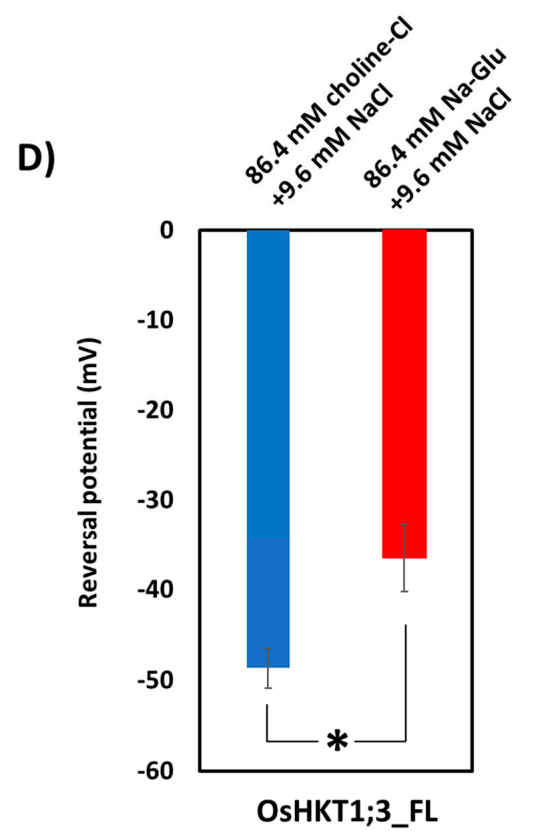

Figure 4. Ion transport activity of OsHKT1;3_FL and its variants. Two electrode voltage clamp experiments using Xenopus laevis oocytes were conducted. (A) Current-voltage relationships from oocytes expressing OsHKT1;3_FL,_V1,_V2, and waterinjection control in a $96 \mathrm{mM} \mathrm{NaCl}$ external solution. (B) Current-voltage relationships from oocytes expressing OsHKT1;3_V3, _V4,_V5, and water-injection control in a $96 \mathrm{mM} \mathrm{NaCl}$ external solution. (C) Current-voltage relationships from oocytes expressing OsHKT1;3_FL in an $86.4 \mathrm{mM}$ choline $\mathrm{Cl}+8.6 \mathrm{mM} \mathrm{NaCl}$ external solution and an $86.4 \mathrm{mM}$ Na-gluconate $+8.6 \mathrm{mM}$ $\mathrm{NaCl}$ external solution. (D) Reversal potential shift analysis conducted by changing the external Na concentration from $96 \mathrm{mM}$ to $9.6 \mathrm{mM}$. All external solutions contained, as background elements, $1.8 \mathrm{mM} \mathrm{CaCl}_{2}, 1.8 \mathrm{mM} \mathrm{MgCl} 2,1.8 \mathrm{mM}$ mannitol, and $10 \mathrm{mM}$ HEPES (pH 7.5 with Tris). Water was injected as a negative control. Data are means $\pm \mathrm{SE}, n=8-10$. Two independent experiments were performed, and similar results were obtained. TEVC data were fitted with polynomial approximations (degree 3) in (A-C). The significant difference in (D) is indicated with an asterisk $(p<0.05)$. 
To determine the affinity of OsHKT1;3 for $\mathrm{Na}^{+}$, the concentrations of $\mathrm{Na}^{+}$in the external medium were changed from 96 to $9.6 \mathrm{mM}$ (Figure 4C). An increase in the extracellular $\mathrm{Na}^{+}$concentration from 9.6 to $96 \mathrm{mM}$ caused approximately $+12 \mathrm{mV}$ reversal potential shifts in oocytes expressing OsHKT1;3_FL (Figure 4D), but no such positive shift was observed in oocytes injected with water (negative control, Supplementary Figure S6), indicating that OsHKT1;3_FL functioned as a $\mathrm{Na}^{+}$-selective transporter. All TEVC data were fitted with polynomial approximations (degree 3 ), and $\mathrm{R}^{2}$ values are described in Supplementary Table S2.

\section{Discussion}

HKTs play important roles in the salt tolerance, ion homeostasis, and distribution of $\mathrm{Na}^{+}$ in plant cells and tissues in salt stress conditions, along with other $\mathrm{Na}^{+}$transporters $[13,14,41]$.

Previously, several splicing variants of OsHKT1;1 have been reported in the salttolerant indica rice, Pokkali [31]. Similarly to OsHKT1;1, it has been reported in a Ph.D. thesis from the University of Adelaide that OsHKT1;3 also produced a spliced variant [40]. In the present study, several splice variants of $O s H K T 1 ; 3$ were confirmed in the salt-sensitive japonica rice, Nipponbare (Figure 1).

Class $1 \mathrm{HKT}$ transporters have been demonstrated to have important roles in $\mathrm{Na}^{+}$ exclusion and salt tolerance mechanisms in several plant species. In rice, the vital role of OsHKT1;1 in $\mathrm{Na}^{+}$exclusion from the shoots, regulation of $\mathrm{Na}^{+}$content in the roots, and the $\mathrm{Na}^{+}$recirculation mechanism from the shoots to the roots was demonstrated [34,42]. The expression of OsHKT1;1 increased in the shoots, but not in the roots [31,42], in salt stress conditions. OsHKT1;5, a $\mathrm{Na}^{+}$-selective transporter, has been indicated to protect leaves, including young ones, in rice through $\mathrm{Na}^{+}$unloading from the xylem of the roots and sheaths, and the phloem at the basal node, in salt stress conditions [22,29,43]. OsHKT1;4 was demonstrated to be involved in $\mathrm{Na}^{+}$exclusion in the stems and leaf sheaths (reducing $\mathrm{Na}^{+}$ in leaf blades) of a japonica rice cultivar at the reproductive growth stage [35]. In addition to these OsHKT1 genes, OsHKT1;3 was reported to be involved in salt tolerance $[29,30]$. The strong expression of OsHKT1;3 in bulliform cells, large, highly vacuolated cells of the adaxial epidermis, may indicate the involvement of $\mathrm{OsHKT1;3}$ in the $\mathrm{Na}^{+}$recirculation mechanisms from the shoots to the roots [29]. However, the detailed physiological functions of $O s H K T 1 ; 3$ are yet to be elucidated. The present study investigated the function of the OsHKT1;3 variants in japonica accessions.

OsHKT1;3_FL, identified in the present study, was most-closely similar to the previously registered OsHKT1;3 (XM_015770707.2) in the National Center for Biotechnology Information (https:/ / www.ncbi.nlm.nih.gov/nuccore/XM_015770707.2, accessed on 27 July 2021). Oocytes expressing OsHKT1;3_FL in the present study showed a small $\mathrm{Na}^{+}$ current (Figure 4A) as reported previously [30]. However, the transport functions and expressions of OsHKT1;3 variants have not been investigated so far. As seen in Figure 4A,B, all oocytes expressing OsHKT1;3 variants showed small currents in the presence of $96 \mathrm{mM}$ $\mathrm{Na}^{+}$. OsHKT1;3_V3,_V4, and _V5 were short-length variants, and oocytes expressing these variants showed slightly larger bidirectional currents (Figure 4B), but the biochemical functions and physiological roles of such variants remain to be investigated.

According to Jabnoune et al. [29], the expression of OsHKT1;3 showed no significant changes in the roots and leaves in different growth conditions. In addition, OsHKT1;3 expression levels in the Pokkali variety were lower in the roots than that of the sensitive cultivar, Nipponbare [37]. Moreover, Farooq et al. [38] reported recently that OsHKT1;3 (OsHKT6) showed high expression in a Cheongcheong rice variety. In the present study, the OsHKT1;3_FL mRNA was the most abundant in both the roots and shoots among the variants identified (Figure 2). This was different from the OsHKT1;1 transcript [31], in which the transcript of OsHKT1;1_FL was less abundant, and a variant (OsHKT1;1_V1) was most abundant.

The expression of OsHKT1;3_FL and some of its variants increased at $24 \mathrm{~h}$ of salt stress (Figure 3), and such results may indicate that $O s H K T 1 ; 3$ and its variants were involved in 
salt tolerance or ion homeostasis at $24 \mathrm{~h}$, at least partially. However, OsHKT1;3 (both FL and all variants) induced only small $\mathrm{Na}+$ currents in the heterologous expression system using X. laevis oocytes (Figure 4), and showed a relatively stable, but not greatly enhanced, expression pattern after $\mathrm{NaCl}$ treatment. These results may suggest that OsHKT1;3 mainly played a supplementary role in salt tolerance or a house-keeping role in rice, unlike other OsHKTs that play critical roles in salt tolerance. The present data, together with previous data, have elucidated various characteristics among OsHKT family members, and will provide insights into how they are involved in the mechanisms of ion homeostasis and salt tolerance in rice.

\section{Materials and Methods}

\subsection{Plant Material and Growth Condition}

A salt-sensitive rice cultivar, Nipponbare, (Oryza sativa L. ssp. japonica) was used in the present study. Seeds were sterilized and germinated as described previously [31]. Seedlings were grown at $28{ }^{\circ} \mathrm{C}$ and $25{ }^{\circ} \mathrm{C}$ for $12 \mathrm{~h}$ in the day $\left(250 \mu \mathrm{mol} \mathrm{m} \mathrm{m}^{-2} \mathrm{~s}^{-1}\right.$ illumination) and $12 \mathrm{~h}$ at night, respectively, for 5 days, and transferred to $3.5 \mathrm{~L}$ pots to grow hydroponically as described previously [31]. Fourteen-day-old plants were sampled for RNA isolation. For the gene expression study, 14-day-old plants were subjected to control ( $0 \mathrm{mM})$, or 25, 50, and $100 \mathrm{mM} \mathrm{NaCl}$ stress for 0,24 , and $48 \mathrm{~h}$, after which the roots and shoots were collected separately.

\subsection{Extraction of DNA and RNA, and Synthesis of $c D N A$}

Nipponbare genomic DNA was extracted from young leaves as described previously [31]. Total RNA extraction, quality and integrity checks, and cDNA synthesis were performed as described previously [31]. OsHKT1;3 cDNAs were amplified using OsHKT1;3 cloning primers (Supplemental Table S1), and cloned into a pCR4 topo vector (Invitrogen, Carlsbad, CA, USA).

\subsection{Expression Analysis}

After reverse transcription with a high-capacity cDNA reverse transcription kit (Applied Biosystem), OsHKT1;3 variants were amplified using specific primers (Supplement Table S1, Supplement Figure S1). Absolute quantification was performed as described previously [44], using the 7300 real-time PCR machine (Applied Biosystem). Specific cDNAs were used as a standard to quantify each variant, and the primer information is indicated in Supplementary Figure S1. The average was calculated from three plants in one experiment, and two independent biological replications were conducted.

\subsection{Expression in Xenopus Laevis Oocytes and Electrophysiology}

OsHKT1;3 cDNAs from Nipponbare were sub-cloned into a pX $\beta G$ vector, and capped RNAs (cRNAs) were synthesized as described previously (Imran et al., 2020). As described previously, the oocytes were isolated and injected with $50 \mathrm{ng} / 50 \mathrm{~nL}$ of OsHKT1;3 cRNA solutions, or with $50 \mathrm{~nL}$ of nuclease-free water (for negative control oocytes), and then incubated at $18{ }^{\circ} \mathrm{C}$ in a modified Barth's solution (MBS) until the electrophysiological recordings [45]. Whole oocyte currents were recorded using the TEVC technique 1 to $2 \mathrm{~d}$ after the cRNA injection as described previously [31]. All electrophysiological experiments were performed at room temperature $\left(20-22{ }^{\circ} \mathrm{C}\right)$. In some experiments, choline was used as a non-permeable cation, and gluconate as a non-permeable anion.

\subsection{Statistical Analyses}

Statistical analyses were performed using IBM SPSS Statistics version 25. Significant differences were identified using a one-way analysis of variance followed by a Tukey HSD $(p<0.05)$ (Figure 2). Data in Figure 3, Figure 4D, and Supplementary Figure S6B were subjected to a $t$-test. Expression data (Figure 3) were compared between controls vs. stress conditions. $p<0.05$ was considered to indicate a statistically significant difference. Regres- 
sion analyses were performed with polynomial approximations (degree 3) for Figure 4A-C, Supplementary Figures S5 and S6A.

Supplementary Materials: The following are available online at https://www.mdpi.com/article/ 10.3390/plants10102006/s1, Table S1: Gene-specific primer pairs used for cloning and in real-time PCR experiments, Table S2: $\mathrm{R}^{2}$ values of all TEVC data, Figure S1: Specific primer position of OsHKT1;3_FL and its five variants for qPCR assays, Figure S2: Nucleotide sequence alignment of Nipponbare OsHKT1;3 genomic DNA and full-length cDNA, Figure S3: Nucleotide sequence alignment of OsHKT1;3_FL and its five variants using GENETYX ver. 13, Figure S4: Protein sequence alignment of OsHKT1;3_FL and its five variants using GENETYX ver. 13, Figure S5: Current-voltage relationships from oocytes expressing OsHKT1;3_FL,_V1,_V2,_V3,_V4,_V5, and water-injection control in $96 \mathrm{mM} \mathrm{KCl}$ external solution, Figure S6: Current-voltage relationships from oocytes expressing water-injected negative control.

Author Contributions: Conceptualization, S.I. and M.K. methodology, M.K.; validation, S.I. and M.K.; formal analysis, S.I.; investigation, S.I., Y.T. and S.T.H.T.; data curation, M.K. writing-original draft preparation, S.I.; writing-review and editing, M.K.; visualization, S.I.; supervision, M.K.; project administration, M.K.; funding acquisition, M.K. All authors have read and agreed to the published version of the manuscript.

Funding: This work was supported by the Ohara Foundation for Agricultural Science (to M.K.).

Institutional Review Board Statement: Not applicable.

Informed Consent Statement: Not applicable.

Data Availability Statement: Gene database of the National Center for Biotechnology Information (https:/ / www.ncbi.nlm.nih.gov, accessed on 30 August 2021).

Acknowledgments: We thank Tomoaki Horie for the scientific discussions.

Conflicts of Interest: The authors declare no conflict of interest. The funders had no role in the design of the study; in the collection, analyses, or interpretation of data; in the writing of the manuscript, or in the decision to publish the results.

\section{References}

1. Kibria, M.; Hoque, M. A Review on Plant Responses to Soil Salinity and Amelioration Strategies. Open J. Soil Sci. 2019, 9, $219-231$. [CrossRef]

2. Hajihashemi, S.; Skalicky, M.; Brestic, M.; Vachová, P. Cross-talk between nitric oxide, hydrogen peroxide and calcium in salt-stressed Chenopodium quinoa Willd. at seed germination stage. Plant Physiol. Biochem. 2020, 154, 657-664. [CrossRef]

3. Rhaman, M.S.; Imran, S.; Karim, M.M.; Chakrobortty, J.; Mahamud, M.A.; Sarker, P.; Tahjib-Ul-Arif, M.; Robin, A.H.K.; Ye, W.; Murata, Y.; et al. 5-aminolevulinic acid-mediated plant adaptive responses to abiotic stress. Plant Cell Rep. 2021, 40, 1451-1469. [CrossRef]

4. Rhaman, M.S.; Imran, S.; Rauf, F.; Khatun, M.; Baskin, C.C.; Murata, Y.; Hasanuzzaman, M. Seed Priming with Phytohormones: An Effective Approach for the Mitigation of Abiotic Stress. Plants 2021, 10, 37. [CrossRef]

5. Rao, P.S.; Mishra, B.; Gupta, S.R. Effects of soil salinity and alkalinity on grain quality of tolerant, semi-tolerant and sensitive rice genotypes. Rice Sci. 2013, 20, 284-291. [CrossRef]

6. Chen, Y.; Wang, Y.; Huang, J.; Zheng, C.; Cai, C.; Wang, Q.; Wu, C.A. Salt and methyl jasmonate aggravate growth inhibition and senescence in Arabidopsis seedlings via the JA signaling pathway. Plant Sci. 2017, 261, 1-9. [CrossRef] [PubMed]

7. Klein, A.; Hüsselmann, L.; Keyster, M.; Ludidi, N. Exogenous nitric oxide limits salt-induced oxidative damage in maize by altering superoxide dismutase activity. S. Afr. J. Bot. 2018, 115, 44-49. [CrossRef]

8. Tahjib-Ul-Arif, M.; Zahan, M.I.; Karim, M.M.; Imran, S.; Hunter, C.T.; Islam, M.S.; Mia, M.A.; Hannan, M.A.; Rhaman, M.S.; Hossain, M.A.; et al. Citric Acid-Mediated Abiotic Stress Tolerance in Plants. Int. J. Mol. Sci. 2021, 22, 7235. [CrossRef]

9. Singh, R.K.; Redoña, E.; Refuerzo, L. Varietal Improvement for Abiotic Stress Tolerance in Crop Plants: Special Reference to Salinity in Rice. In Abiotic Stress Adaptation in Plants; Pareek, A., Sopory, S., Bohnert, H., Eds.; Springer: Dordrecht, The Netherland, 2009. [CrossRef]

10. Dawe, D.; Pandey, S.; Nelson, A. Emerging trends and spatial patterns of rice production. In Rice in the Global Economy: Strategic Research and Policy Issues for Food Security; International Rice Research Institute (IRRI): Los Baños, Philippines, 2010 ; pp. 15-35.

11. Corratge'-Faillie, C.; Jabnoune, M.; Zimmermann, S.; Ve'ry, A.A.; Fizames, C.; Sentenac, H. Potassium and sodium transport in non-animal cells, the Trk/Ktr/HKT transporter family. Cell. Mol. Life Sci. 2010, 67, 2511-2532. [CrossRef] [PubMed]

12. Sassi, A.; Mieulet, D.; Khan, I.; Moreau, B.; Gaillard, I.; Sentenac, H.; Véry, A.A. The rice monovalent cation transporter OsHKT2;4, revisited ionic selectivity. Plant Physiol. 2012, 160, 498-510. [CrossRef] 
13. Rubio, F.; Nieves-Cordones, M.; Horie, T.; Shabala, S. Doing 'business as usual' comes with a cost: Evaluating energy cost of maintaining plant intracellular $\mathrm{K}^{+}$homeostasis under saline conditions. New Phytol. 2019, 225, 1097-1104. [CrossRef]

14. Platten, J.D.; Cotsaftis, O.; Berthomieu, P.; Bohnert, H.; Davenport, R.J.; Fairbairn, D.J.; Horie, T.; Leigh, R.A.; Lin, H.X.; Luan, S.; et al. Nomenclature for HKT transporters, key determinants of plant salinity tolerance. Trends Plant Sci. 2006, 11, 372-374. [CrossRef]

15. Haro, R.; Banuelos, M.A.; Rodriguez-Navarro, A. High-affinity sodium uptake in land plants. Plant Cell Physiol. 2010, 51, 68-79. [CrossRef]

16. Almeida, P.; Katschnig, D.; De Boer, A.H. HKT Transporters-State of the Art. Int. J. Mol. Sci. 2013, 14, 20359-20385. [CrossRef]

17. Asins, M.J.; Villalta, I.; Aly, M.M.; Olías, R.; Alvarez DE Morales, P.; Huertas, R.; Li, J.; Jaime-Pérez, N.; Haro, R.; Raga, V.; et al. Two closely linked tomato HKT coding genes are positional candidates for the major tomato QTL involved in $\mathrm{Na}^{+} / \mathrm{K}^{+}$homeostasis. Plant Cell Environ. 2013, 36, 1171-1191. [CrossRef] [PubMed]

18. Waters, S.; Gilliham, M.; Hrmova, M. Plant high-affinity potassium (HKT) transporters involved in salinity tolerance: Structural insights to probe differences in ion selectivity. Int. J. Mol. Sci. 2013, 14, 7660-7680. [CrossRef] [PubMed]

19. Gassmann, W.; Rubio, F.; Schroeder, J.I. Alkali cation selectivity of the wheat root high-affinity potassium transporter HKT1. Plant J. 1996, 10, 869-952. [CrossRef]

20. Horie, T.; Brodsky, D.E.; Costa, A.; Kaneko, T.; Lo Schiavo, F.; Katsuhara, M.; Schroeder, J.I. K ${ }^{+}$transport by the OsHKT2;4 transporter from rice with atypical $\mathrm{Na}^{+}$transport properties and competition in permeation of $\mathrm{K}^{+}$over $\mathrm{Mg}^{2+}$ and Ca ${ }^{2+}$ ions. Plant Physiol. 2011, 156, 1493-1507. [CrossRef] [PubMed]

21. Rus, A.; Lee, B.H.; Muñoz-Mayor, A.; Sharkhuu, A.; Miura, K.; Zhu, J.K.; Bressan, R.A.; Hasegawa, P.M. AtHKT1 facilitates Na ${ }^{+}$ homeostasis and $\mathrm{K}^{+}$nutrition in planta. Plant Physiol. 2004, 136, 2500-2511. [CrossRef] [PubMed]

22. Ren, Z.H.; Gao, J.P.; Li, L.G.; Cai, X.L.; Huang, W.; Chao, D.Y.; Zhu, M.Z.; Wang, Z.Y.; Luan, S.; Lin, H.X. A rice quantitative trait locus for salt tolerance encodes a sodium transporter. Nat. Genet. 2005, 37, 1141-1146. [CrossRef] [PubMed]

23. Sunarpi; Horie, T.; Motoda, J.; Kubo, M.; Yang, H.; Yoda, K.; Horie, R.; Chan, W.Y.; Leung, H.Y.; Hattori, K.; et al. Enhanced salt tolerance mediated by AtHKT1 transporter-induced Na unloading from xylem vessels to xylem parenchyma cells. Plant J. 2005, 44, 928-938. [CrossRef]

24. Møller, I.S.; Gilliham, M.; Jha, D.; Mayo, G.M.; Roy, S.J.; Coates, J.C.; Haseloff, J.; Tester, M. Shoot Na ${ }^{+}$exclusion and increased salinity tolerance engineered by cell type-specific alteration of $\mathrm{Na}^{+}$transport in Arabidopsis. Plant Cell 2009, 21, $2163-2178$. [CrossRef]

25. Chen, H.T.; He, H.; Yu, D.Y. Overexpression of a novel soybean gene modulating $\mathrm{Na}^{+}$and $\mathrm{K}^{+}$transport enhances salt tolerance in transgenic tobacco plants. Physiol. Plant 2011, 141, 11-18. [CrossRef] [PubMed]

26. Han, Y.; Yin, S.; Huang, L.; Wu, X.; Zeng, J.; Liu, X.; Qiu, L.; Munns, R.; Chen, Z.H.; Zhang, G. A Sodium Transporter HvHKT1;1 Confers Salt Tolerance in Barley via Regulating Tissue and Cell Ion Homeostasis. Plant Cell Physiol. 2018, 59, 1976-1989. [CrossRef] [PubMed]

27. Kawakami, Y.; Imran, S.; Katsuhara, M.; Tada, Y. Na ${ }^{+}$Transporter SvHKT1;1 from a Halophytic Turf Grass Is Specifically Upregulated by High $\mathrm{Na}^{+}$Concentration and Regulates Shoot $\mathrm{Na}^{+}$Concentration. Int. J. Mol. Sci. 2020, 21, 6100. [CrossRef]

28. Garciadeblás, B.; Senn, M.E.; Bañuelos, M.A.; Rodríguez-Navarro, A. Sodium transport and HKT transporters: The rice model. Plant J. 2003, 34, 788-801. [CrossRef]

29. Jabnoune, M.; Espeout, S.; Mieulet, D.; Fizames, C.; Verdeil, J.L.; Conéjéro, G.; Rodríguez-Navarro, A.; Sentenac, H.; Guiderdoni, E.; Abdelly, C.; et al. Diversity in expression patterns and functional properties in the rice HKT transporter family. Plant Physiol. 2009, 150, 1955-1971. [CrossRef] [PubMed]

30. Rosas-Santiago, P.; Lagunas-Gómez, D.; Barkla, B.J.; Vera-Estrella, R.; Lalonde, S.; Jones, A.; Frommer, W.B.; Zimmermannova, O.; Sychrová, H.; Pantoja, O. Identification of rice cornichon as a possible cargo receptor for the Golgi-localized sodium transporter OsHKT1;3. J. Exp. Bot. 2015, 66, 2733-2748. [CrossRef]

31. Imran, S.; Horie, T.; Katsuhara, M. Expression and Ion Transport Activity of Rice OsHKT1;1 Variants. Plants 2020, 9, 16. [CrossRef] [PubMed]

32. Somasundaram, S.; Véry, A.A.; Vinekar, R.S.; Ishikawa, T.; Kumari, K.; Pulipati, S.; Kumaresan, K.; Corratgé-Faillie, C.; Sowdhamini, R.; Parida, A.; et al. Homology Modeling Identifies Crucial Amino-Acid Residues That Confer Higher Na ${ }^{+}$ Transport Capacity of OcHKT1;5 from Oryza coarctata Roxb. Plant Cell Physiol. 2020, 61, 1321-1334. [CrossRef]

33. Takagi, H.; Tamiru, M.; Abe, A.; Yoshida, K.; Uemura, A.; Yaegashi, H.; Obara, T.; Oikawa, K.; Utsushi, H.; Kanzaki, E.; et al. MutMap accelerates breeding of a salt-tolerant rice cultivar. Nat. Biotechnol. 2015, 33, 445-449. [CrossRef]

34. Campbell, M.T.; Bandillo, N.; Al Shiblawi, F.R.A.; Sharma, S.; Liu, K.; Du, Q.; Schmitz, A.J.; Zhang, C.; Very, A.A.; Lorenz, A.J.; et al. Allelic variants of OsHKT1;1 underlie the divergence between indica and japonica subspecies of rice (Oryza sativa) for root sodium content. PLoS Genet. 2017, 13, e1006823. [CrossRef] [PubMed]

35. Suzuki, K.; Yamaji, N.; Costa, A.; Okuma, E.; Kobayashi, N.I.; Kashiwagi, T.; Katsuhara, M.; Wang, C.; Tanoi, K.; Murata, Y.; et al. OsHKT1;4-mediated $\mathrm{Na}^{+}$transport in stems contributes to $\mathrm{Na}^{+}$exclusion from leaf blades of rice at the reproductive growth stage upon salt stress. BMC Plant Biol. 2016, 16, 22. [CrossRef] [PubMed]

36. Oda, Y.; Kobayashi, N.I.; Tanoi, K.; Ma, J.F.; Itou, Y.; Katsuhara, M.; Itou, T.; Horie, T. T-DNA tagging-based gain-of-function of OsHKT1;4 reinforces Na exclusion from leaves and stems but triggers Na toxicity in roots of rice under salt stress. Int. J. Mol. Sci. 2018, 19, 235. [CrossRef] [PubMed] 
37. Do, P.T.; Hoang, Y.H.; Le, M.Q.; Tang, H.T.; Nguyen, D.H. OsHKT1;3 gene sequence polymorphisms and expression profile in rice (Oryza sativa L.). Afr. J. Agric. Res. 2018, 13, 2659-2667. [CrossRef]

38. Farooq, M.; Park, J.R.; Jang, Y.H.; Kim, E.G.; Kim, K.M. Rice Cultivars under Salt Stress Show Differential Expression of Genes Related to the Regulation of $\mathrm{Na}^{+} / \mathrm{K}^{+}$Balance. Front. Plant Sci. 2021, 12, 680131. [CrossRef]

39. Abdulhussein, F.R.; Mutlag, N.H.; Sarheed, A.F. Genotypic characterization and tissue localization of the mutant lines expression of HKT1;3 gene in rice under salt stress. Plant Arch. 2018, 18, 489-495.

40. Sundstrom, J.F. Role and control of HKT in Oryza sativa \& Arabidopsis thaliana. Ph.D. Thesis, University of Adelaide, Adelaide, Australia, 2011. Available online: http:/ / hdl.handle.net/2440/68832 (accessed on 24 September 2021).

41. Hauser, F.; Horie, T. A conserved primary salt tolerance mechanism mediated by HKT transporters: A mechanism for sodium exclusion and maintenance of high $\mathrm{K}^{+} / \mathrm{Na}^{+}$ratio in leaves during salinity stress. Plant Cell Environ. 2010, 33, 552-565. [CrossRef]

42. Wang, R.; Jing, W.; Xiao, L.; Jin, Y.; Shen, L.; Zhang, W. The Rice High-Affinity Potassium Transporter1;1 Is Involved in Salt Tolerance and Regulated by an MYB-Type Transcription Factor. Plant Physiol. 2015, 168, 1076-1090. [CrossRef]

43. Kobayashi, N.I.; Yamaji, N.; Yamamoto, H.; Okubo, K.; Ueno, H.; Costa, A.; Tanoi, K.; Matsumura, H.; Fujii-Kashino, M.; Horiuchi, T.; et al. OsHKT1;5 mediates $\mathrm{Na}^{+}$exclusion in the vasculature to protect leaf blades and reproductive tissues from salt toxicity in rice. Plant J. 2017, 91, 657-670. [CrossRef]

44. Mahdieh, M.; Mostajeran, A.; Horie, T.; Katsuhara, M. Drought stress alters water relations and expression of PIP-type aquaporin genes in Nicotiana tabacum plants. Plant Cell Physiol. 2008, 49, 801-813. [CrossRef] [PubMed]

45. Katsuhara, M.; Akiyama, Y.; Koshio, K.; Shibasaka, M.; Kasamo, K. Functional analysis of water channels in barley roots. Plant Cell Physiol. 2002, 43, 885-893. [CrossRef] [PubMed] 